\title{
A Mechanistic Approach for the Prediction of Critical Power in BWR Fuel Bundles*
}

\author{
Dinesh Kumar CHANDRAKER**, Pallipattu Krishnan VIJAYAN**, \\ Ratan Kumar SINHA** and Masanori ARITOMI*** \\ ** Reactor Design and Development Group, Bhabha Atomic Research Centre \\ Trombay, Mumbai-400085, India \\ E-mail: dineshkc@barc.gov.in \\ *** Research Laboratory for Nuclear Reactors, Tokyo Institute of Technology, \\ 2-12-1, Ookayama, Meguro-ku, Tokyo, 152-8550, Japan
}

\begin{abstract}
The critical power corresponding to the Critical Heat Flux (CHF) or dryout condition is an important design parameter for the evaluation of safety margins in a nuclear fuel bundle. The empirical approaches for the prediction of CHF in a rod bundle are highly geometric specific and proprietary in nature. The critical power experiments are very expensive and technically challenging owing to the stringent simulation requirements for the rod bundle tests involving radial and axial power profiles. In view of this, the mechanistic approach has gained momentum in the thermal hydraulic community. The Liquid Film Dryout (LFD) in an annular flow is the mechanism of CHF under BWR conditions and the dryout modeling has been found to predict the CHF quite accurately for a tubular geometry. The successful extension of the mechanistic model of dryout to the rod bundle application is vital for the evaluation of critical power in the rod bundle. The present work proposes the uniform film flow approach around the rod by analyzing individual film of the subchannel bounded by rods with different heat fluxes resulting in different film flow rates around a rod and subsequently distributing the varying film flow rates of a rod to arrive at the uniform film flow rate as it has been found that the liquid film has a strong tendency to be uniform around the rod. The FIDOM-Rod code developed for the dryout prediction in BWR assemblies provides detailed solution of the multiple liquid films in a subchannel. The approach of uniform film flow rate around the rod simplifies the liquid film cross flow modeling and was found to provide dryout prediction with a good accuracy when compared with the experimental data of 16,19 and 37 rod bundles under BWR conditions. The critical power has been predicted for a newly designed 54 rod bundle of the Advanced Heavy Water Reactor (AHWR). The selected constitutive models for the droplet entrainment and deposition rates validated for the dryout in tube were also found to perform well for the rod bundle under BWR conditions.
\end{abstract}

Key words: Critical Power, CHF, Liquid Film Dryout, Mechanistic Modeling, BWR

\section{Introduction}

The critical power is an important consideration for the thermal design of nuclear fuel bundle. The nuclear fuel bundle must be operated well below the CHF to allow for the operating flexibility and uncertainty in the prediction. Enormous amount of CHF data has been generated in the past and a number of empirical correlations on CHF have been developed for various experimental conditions. The applicability of these empirical correlations is within the range of their experiments. As of now, there exist more than 1000

*Received 19 Dec., 2011 (№. 11-0780) [DOI: 10.1299/jpes.6.35]

Copyright $\odot 2012$ by JSME 
correlations [1] just for a tube cooled by water which is due to the complex underlying mechanisms. Thus, under the reactor condition, the generation of the full scale experimental data is indispensable due to the limitations posed by the empirical approach as any change in geometry and operating conditions causes profound impact on the value of CHF. Since the CHF phenomenon is very much dependent on the two-phase flow pattern; it is possible to develop mechanistic models to achieve wider range of validity. Under the BWR conditions (high quality), the CHF is caused due to the progressive depletion of the liquid film over the heated surface (Fig. 1). This phenomenon is generally referred to as Liquid Film Dryout (LFD). The phenomenological (mechanistic) models for LFD have been suggested by various investigators. Representative models are due to Levy [2], Saito et al. [3], Katto[4], Sugawara [5] and Hoyer[6] with different level of success. Over the years there have been significant improvements in the mechanistic prediction of dryout. Mechanistic prediction for a simple geometry has been found to be very good under BWR conditions as investigated by Utsuno et al. [7] and Chandraker et al. [8].

There have been numerous efforts to predict the dryout in rod bundle also using the mechanistic approach. Codes like SILFEED [9.10,11], FIDAS[12], CAPE-BWR[13], COBRA/BWR[14] etc. have been developed and compared with the experimental data achieving good accuracy. Whalley [15] predicted dryout in a bundle using rod centered subchannel approach. Another approach is to use the existing subchannel code as a driver tool which provides the subchannel conditions to the film dryout code. Adamsson et al.[16] adopted similar approach using film flow code MEFISTO. The MEFISTO tool demonstrated that decoupling of the dryout analysis from the subchannel code is a feasible option and this approach promises to accommodate complex situation like part length fuel, unheated wall etc. with enough flexibility.

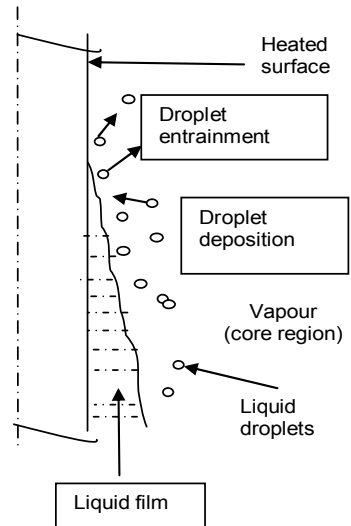

Fig. 1 Progressive depletion of the liquid film and three fluid steams

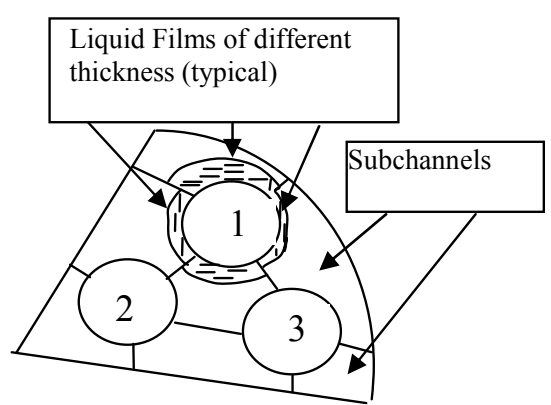

Fig. 2 Typical formation of liquid film on the rod surfaces facing different subchannels

The constitutive models for the droplet entrainment and deposition rates play an important role for the good accuracy of the dryout prediction and hence the models tested for tube under the BWR operating conditions $[7,8]$ has also been applied to the rod bundle in the present work using the subchannel conditions derived from the subchannel code COBRA-IV-I[17]. The lateral flow rate of the film on the rod is also an important aspect of the dryout modeling and the previous approaches mentioned above generally assume that the cross flow consists of vapor only and liquid contribution is negligible [15]. However, liquid film cross flow cannot be avoided as the rod is surrounded with the subchannel having different mass flux and droplet content. Whalley [18] assumed a uniform film flow rate with the rod centric subchannels. However, coolant centered subchannel represents 
better simulation for the varying subchannel conditions around the rod. The film flow on the rod has a strong tendency to be uniform as mentioned by Whalley [18] and Butterworth [19].

In view of the above considerations, the present approach proposes the modeling of liquid film on the rod considering uniform flow around the rod allowing lateral cross flow of the films. Also, the validated constitutive models for the entrainment and deposition are important for the good accuracy of the dryout prediction. The constitutive models for the entrainment and deposition rates incorporated in the code FIDOM[7] for dryout prediction in a tube has also been employed in the extended version of this code (FIDOM-Rod) for the bundle application.

To validate the approach, the critical power test data for 16, 19 and 37 rod bundles has been compared with the prediction of FIDOM-Rod. The approach is found to yield good accuracy for the rod bundle under BWR conditions. Subsequently, the critical power of untested 54 rod bundle of AHWR has been predicted for various operating conditions.

\section{Nomenclature}

$\begin{array}{llll}\mathrm{D} & : \text { Diameter }(\mathrm{m}) & \mathrm{e} & : \text { Entrainment } \\ \mathrm{g} & : \text { Gravitational constant }\left(\mathrm{m} / \mathrm{s}^{2}\right) & \mathrm{ev} & : \text { Evaporation } \\ \mathrm{k} & : \text { Mass transfer coefficient }(\mathrm{m} / \mathrm{s}) & \text { eq } & : \text { Value at equilibrium } \\ \mathrm{m} & : \text { Mass transfer rate }\left(\mathrm{kg} / \mathrm{m}^{2} \mathrm{~s}\right) & \text { lf } & : \text { Liquid film } \\ \mathrm{N} \mu & : \text { Viscosity number } & \mathrm{scl} & : \text { Subchannel liquid } \\ \mathrm{P} & : \text { Perimeter of the heated surface } & \mathrm{scld} & : \text { Subchannel droplet } \\ \mathrm{q} " & : \text { Heat flux }\left(\mathrm{MW} / \mathrm{m}^{2}\right) & \mathrm{sclf} & : \text { Subchannel liquid film } \\ \mathrm{W} & : \text { Mass flow rate }(\mathrm{kg} / \mathrm{s}) & \mathrm{sclfi} & : \text { At onset of annular flow } \\ \mathrm{X} & : \text { Quality } & \mathrm{lfi} & : \text { At onset of annular flow } \\ \mathrm{Greek} \text { Symbol } & \mathrm{cf} & : \text { Cross flow } \\ \rho & : \text { Density }\left(\mathrm{kg} / \mathrm{m}^{3}\right) & \mathrm{lcf} & : \text { Liquid cross flow } \\ \mu & : \text { Viscosity }\left(\mathrm{Ns} / \mathrm{m}^{2}\right) & \mathrm{gcf} & : \text { Gas cross flow } \\ \sigma & : \text { Surface tension }(\mathrm{N} / \mathrm{m}) & \mathrm{g} & : \text { Gas phase } \\ \text { Subscripts } & 1 & : \text { Liquid phase } \\ \text { ld } & : \text { Liquid droplet } & \mathrm{rld} & : \text { Total liquid flow in a rod } \\ \mathrm{d} & : \text { Deposition } & \mathrm{k} & : \text { Liquid film number }\end{array}$

\section{Assumptions for the LFD analysis}

In the liquid film analysis, the conservation equations of mass and energy for the liquid film is solved. Since the film dryout modeling for a rod bundle utilizes the subchannel information derived from the subchannel code, certain assumptions are required to be made to simplify the analysis.

1) Each subchannel is assumed to behave like a tube considering cross flow and mixing as is done in the subchannel approach.

2) The mass flux, quality and the exchange of liquid and vapour between the subchannels is dictated by subchannel formulation. As the total liquid flow rate in the subchannel comprises the film flow rate and droplet flow rate, the droplet content in the vapour core changes axially depending on the deposition rate, entrainment rate and film evaporation rate in the subchannel.

3) The fuel rod experiences different entrainment and deposition rates circumferentially as it is facing different subchannel conditions (fig. 2). Thus film flow rate around the rod need not be uniform but these segments of the films around the rod will have mass exchange also as they are not physically separated. However, the process of exchange of 
liquid film around the rod is a complex phenomenon and there is a strong tendency to achieve uniformity in the film flow rate in the circumferential direction as mentioned by Whalley [17] and Butterworth [18]. Hence, in the present analysis after the individual film flow calculations, the film flow rate is made uniform before proceeding to the next node.

4) The dryout is initiated when the film flow rate on any one the rods reduces to zero and the liquid film vanishes. It is assumed that at the onset of dryout of some part of the rod, the remaining wetted surface is also very close to dryout so that any small increase in power beyond the dryout would lead to complete dryout of the rod at a given axial location. This assumption leads to simplicity in calculation of the liquid film cross flow by making the film flow uniform before proceeding to the next node while preserving the mass balance for liquid and vapor content as calculated by the subchannel code.

\section{Description of the models of the LFD analysis (FIDOM-Rod)}

As discussed earlier, COBRA-IV-I [17] has been used as the driver module to determine the subchannel conditions and the film dryout code (FIDOM-Rod) is used for the film dryout analysis. COBRA-IV-I is a well established code which is used for the thermal hydraulic analysis of the nuclear rod bundle. It uses a mathematical model that considers both turbulent mixing and diversion cross flow between adjacent subchannels. Each subchannel is assumed to contain one-dimensional, two-phase, separated, slip flow. The models of COBRA-IV-I are given in the reference [9]. In general any subchannel code can be used to provide the local conditions of the rod bundle to the dryout code, FIDOM-Rod. The model description of the dryout module is given below.

The code FIDOM-Rod (Film Dryout Modeling in Rod Bundle) is the extended version of the code, FIDOM [8] which was developed and validated for a dryout in a tube. The code, FIDOM-Rod uses the subchannel conditions determined by the subchannel code and initiates the film analysis as soon as the annular flow pattern prevails in the subchannels. The modeling is based on the entrainment and deposition of the droplet in an annular flow regime. The important aspects of the modeling are the mass exchange at the interface between the liquid film and the vapour core region (Fig. 1). The wavy characteristic of the interface leads to the entrainment of the droplet from the liquid film to the vapour core. The droplet deposition on to the liquid film also takes place causing the buildup of the liquid layer which enhances the film thickness. Another important aspect is the determination of the inceptions of the annular flow and of the droplet entrainment. In the code, FIDOM-Rod, the constitutive correlations for the entrainment, deposition and onset of annular flow have been considered which are same as that incorporated in the FIDOM. The conservation equations for the liquid film flow analysis and constitutive models for entrainment and deposition are described below.

\subsubsection{Conservation equations for the LFD Module:}

Mass balance of the liquid film $(\mathrm{k})$ in a subchannel is given by

$\frac{d w_{l f}^{k}}{d z}=P^{k}\left(m_{d}-m_{e}-m_{e v}\right)_{k}+\frac{d w_{l f_{-} c f}^{k}}{d z}$

Liquid film mass conservation for the subchannel having ' $n$ ' liquid films

$\frac{d w_{s c l f}}{d z}=\sum_{k=1}^{n} P^{k}\left(m_{d}-m_{e}-m_{e v}\right)_{k}+\frac{d w_{s c l f \_c f}}{d z}$

For the droplets in a subchannel surrounded by ' $n$ ' number of liquid films 
$\frac{d w_{\text {scld }}}{d z}=\sum_{k=1}^{n} P^{k}\left(m_{e}-m_{d}\right)_{k}+\frac{d w_{\text {scld_cf }}}{d z}$

Total liquid flow composed of liquid film and droplets is computed by SCAM as given by equation 4.

$\frac{d w_{s c l}}{d z}=\frac{d w_{s c l f}}{d z}+\frac{d w_{s c l d}}{d z}$

Similarly, the cross flow of the liquid is composed of liquid film and droplets

$\frac{d w_{\text {scl_cf }}}{d z}=\frac{d w_{\text {sclf_cf }}}{d z}+\frac{d w_{\text {scld_cf }}}{d z}$

Thus the droplet flow rate in a subchannel is calculated from equation 4 using the results of subchannel module and dryout module. Thus the dropet flow rate is given by

$\frac{d w_{s c l d}}{d z}=\frac{d w_{s c l}}{d z}-\frac{d w_{s c l f}}{d z}$

For the gas

$\frac{d w_{g}}{d z}=\sum_{=1}^{n} P^{k} m_{e v}+\frac{d w_{g c f}}{d z}$

The loss of liquid due to evaporation of each film is taken into account in the liquid film dryout analysis (FIDOM-ROD) depending upon the rod peaking factor and axial peaking factor. However, the gas flow is dictated by the subchannel analysis code.

Energy balance in a given subchannel is

$m_{e v}=\sum_{k=1}^{n} \frac{q_{k}}{h_{f g}}$

After calculating the film flow rate in the rod surfaces for all the subchannels, the film flow rate around any rod is averaged circumferentially at each axial location before proceeding for the analysis for the next node. Thus film flow rate is averaged considering ' 1 ' number of liquid film around the rod as given below.

$$
\begin{aligned}
& w_{r l f}=\sum_{k=1}^{l} w_{l f}^{k} \\
& \left(w_{l f}^{k}\right)_{\text {updated }}=\frac{w_{r l f} P^{k}}{\sum_{k=1}^{n} P^{k}}
\end{aligned}
$$

Where, $\left(\mathrm{w}^{\mathrm{k}}{ }_{\mathrm{lf}}\right)_{\text {updated }}$ is the updated value of film flow rate in the surface $(\mathrm{k})$ of the rod.

Mass Transfer equations: The mass transfer correlations for the entrainment and deposition of the liquid droplets proposed by Whalley [20] are given below.

$m_{e}=K C_{e q}$

$m_{d}=K C$

Where $\mathrm{K}$ is the mass transfer coefficient and $\mathrm{C}$ is the droplet concentration prevailing in subchannel. $\mathrm{C}_{\mathrm{eq}}$ is the liquid concentration at equilibrium which is related to the entrainment.

The droplet mass per unit volume is given by 


$$
C=\frac{\rho_{l} j_{l d}}{j_{g}+j_{l d}}=\frac{\rho_{l} j_{l} E}{j_{g}+j_{l} E}
$$

Where $\mathrm{j}_{\mathrm{g}}$ and $\mathrm{j}_{1}$ are the superficial velocities for the gas and liquid droplets in the subchannel respectively.

$\mathrm{E}$ is the entrainment fraction defined as the ratio of the entrained liquid droplets to the total liquid in the subchannel. The entrainment fraction in a subchannel is calculated considering the quality and the liquid film flow rate in the subchannel. This ensures that the cross flow information is passed on to LFD module in terms of the droplet concentration. The droplet entrainment fraction is the fraction of liquid entrained in the gas core defined by

$$
E=\frac{J_{l d}}{J_{l}}
$$

\subsubsection{Constitutive models for the deposition coefficient and entrainment rate}

The constitutive correlations for the deposition coefficient and entrainment are the important for the dryout prediction and hence validated models for a tube (FIDOM) has been incorporated in the present approach.

Entrainment Fraction at Equilibrium (Eeq): Modified form of the model for Ishii and Mishima[21] has been used. The modified form was proposed by Utsuno and Kaminaga [7] for the BWR operating range and diabatic conditions.

$$
E_{e q}=\tanh \left(0.16 W_{e}^{0.08} R_{e l}^{0.16}-1.2\right)
$$

Where We is the Weber number defined as

$$
W_{e}=\frac{\rho_{g} j_{g} D}{\sigma}\left(\frac{\Delta \rho}{\rho_{g}}\right)^{1 / 2}
$$

$\mathrm{Re}_{1}$ is the liquid Reynolds number defined by

$$
\operatorname{Re}_{l}=\frac{\rho_{l} j_{l} D}{\mu_{l}}
$$

The applicable range of this correlation is within a pressure of 3 to $9 \mathrm{MPa}$, entrainment Weber number, We of $2.6 \times 10^{2}$ to $8.3 \times 10^{4}$ and total liquid Reynolds number $R_{1}$ of $5.4 \times 10^{2}$ to $3.5 \times 10^{5}$

Mass Transfer Coefficient or deposition Coefficient (K): The model of Paleev and Filippovich [22] was modified by Utsuno and Kaminaga [7] to achieve better prediction in the BWR operating range and diabatic conditions.

$$
K=41.2 \frac{\mu_{g}}{\rho_{g} D} R_{e g}^{0.15}\left(\frac{C}{\rho_{g}}\right)^{-0.36}
$$

$\mathrm{Re}_{\mathrm{g}}$ is the Reynolds number for gas. The applicable range of pressure is at $6.9 \mathrm{Mpa}$ but Utsuno and Kaminaga [7] could successfully predict the dryout in a tube over the range from of 3 to $9 \mathrm{MPa}, \mathrm{C} / \rho_{\mathrm{g}}$ of 0.6 to 6.8 and the gas Reynolds number $\mathrm{Re}_{\mathrm{g}}$ of $1.6 \times 10^{5}$ to 6.6x10 . Also, Chandraker et al. [8] predicted over the pressure range from 2.9-7.14 MPa for over 125 data points with a good accuracy.

This correlation was found to be comparable with that of Okawa et al.[23] even beyond the validity range of $\mathrm{C} / \rho_{\mathrm{g}}$ of Utsuno's model. The above correlations for the mass transfer and the equilibrium entrainment have been used in the FIDOM and its dryout prediction has been validated under the BWR conditions. Hence, the same correlations have been used for the FIDOM-Rod also for the critical power prediction in the fuel assembly of BWR. 
The correlation proposed by Okawa [23] for the mass transfer coefficients is given below $K \sqrt{\frac{\rho_{g} D}{\sigma}}=0.0632\left(\frac{C}{\rho_{g}}\right)^{-0.5}$ This is valid over the entire range of $\left(\mathrm{C} / \rho_{\mathrm{g}}\right)$.

\subsubsection{Inception of the entrainment of droplets:}

When a gas phase is flowing over the liquid film, the interfacial wave grows with the increase of gas velocity. As the gas phase velocity is increased, a roll wave with large amplitude is generated. The droplet entrainment starts when the retaining force of the surface tension is exceeded by the interfacial shear force exerted by streaming gas flow. Ishii and Glormes [25] has suggested a simple model for $\operatorname{Re}_{1 f}>163$ as follow:

$$
\begin{aligned}
\frac{\mu_{l} j_{g c}}{\sigma} \sqrt{\frac{\rho_{g}}{\rho_{l}}}=N_{\mu}^{0.8} & \text { for } & N_{\mu}^{0.8}<\frac{1}{15} \\
\frac{\mu_{l j_{g c}}}{\sigma} \sqrt{\frac{\rho_{g}}{\rho_{l}}}=0.1146 & \text { for } & N_{\mu}>\frac{1}{15}
\end{aligned}
$$

Where $N_{\mu \text { is a viscosity number given by }}$

$$
N_{\mu}=\frac{\mu_{l}}{\left(\rho_{l} \sigma \sqrt{\frac{\sigma}{g \Delta \rho}}\right)^{1 / 2}}
$$

The onset of entrainment criterion is given as follow.

$$
j_{g}>j_{g c}
$$

Where $J_{g}$ is the volumetric gas flux and $J_{g c}$ is the critical volumetric flux for gas for the entrainment inception.

\subsubsection{Initial film flow rate at the onset of annular flow:}

The initial entrainment fraction right after the transition to the annular-mist flow is assumed to be at equilibrium.

$E=E_{e q}$

The equilibrium droplet concentration in a subchannel is given by

$$
C_{e q}=\frac{\rho_{l} j_{l} E_{e q}}{j_{g}+j_{l} E_{e q}}
$$

The total film flow rate in the subchannel at the onset of the annular flow gets distributed to the associated rod surfaces of the subchannel in the proportion of the surface area facing the subchannel.

$$
\text { i.e }\left(w_{l f i}^{k}\right)=\frac{w_{s c l f} P^{k}}{\sum_{k=1}^{n} P^{k}}
$$

Once the initial film flow rate is set at the onset of the annular flow rate, the flow rate of individual films on the rod and the droplet concentration depends on the film evaporation, entrainment and deposition.

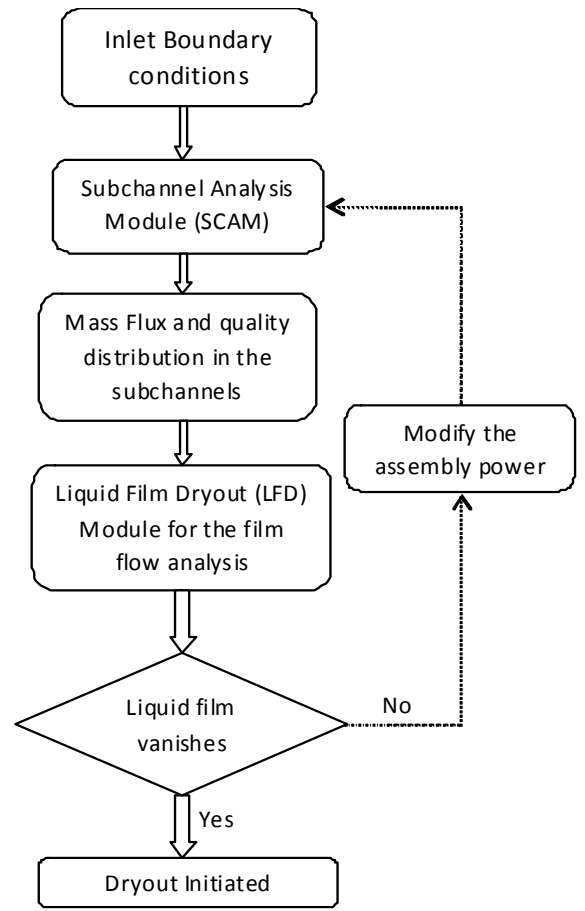

Fig. 3 Interface between the liquid film dryout and subchannel analysis modules 


\section{Interfacing with the subchannel code}

At first, the subchannel analysis is performed for a given assembly power using Subchannel Analysis Module (SCAM). The subchannel enthalpy and mass flux are the input to the Liquid Film Dryout Analysis Module (LFDAM). The location of the onset of droplet entrainment is determined for each subchannel which is the starting point for the progression of the liquid film. Once the annular flow predicted for all the subchannels facing the rod under consideration, the dryout analysis is triggered for this rod. The initial liquid film flow rate corresponds to the equilibrium droplet concentration (Eqs. 24-26). Thus the code of LFDAM module (FIDOM-Rod) analyses each film in the subchannels considering different entrainment rate, deposition rate evaporation rate depending upon the rod power peaking. Once the flow rate of each film is analyzed swiping the entire cross section, the liquid film flow rate around the rod at any axial location is made uniform circumferentially. In this process, the cross flow of the liquid films take place to maintain uniform liquid flow rate around the rod and the starving part of the rod (or the section with lower flow rate) is replenished by the remaining liquid films of the rod maintaining the total liquid film flow rate of the rod conserved. The film flow rate in each rod is examined and if none of the rod has zero film flow rate indicating that dryout is not attained, the power of the channel is further increased and subchannel condition is obtained to feed the LFDA module. This iteration is repeated till the dryout condition is achieved. Fig. 3 shows the flow chart of the analysis indicating the interfacing between the driver module, SCAM and the dryout module, LFDAM.

\section{Dryout Criterion}

Dryout criterion for the high quality CHF relevant to BWR conditions is generally based on the vanishing of the film flow on the rod. However, there could be a formation of drypatches or revulets due to the unstable thin film before the complete dryout. Previous investigations confirms that such critical film thickness at which dry patches starts developing on the heated rod is
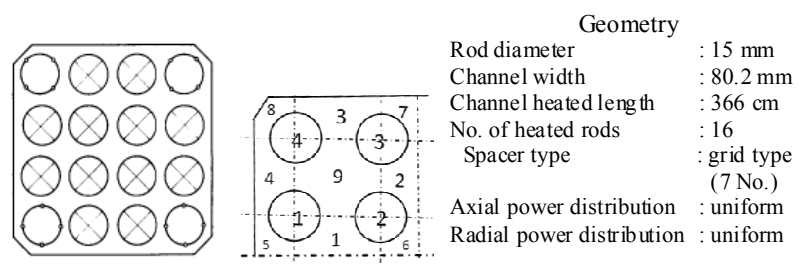

Fig. 416 rod bundle cross section and $1 / 4$ symmetry sector
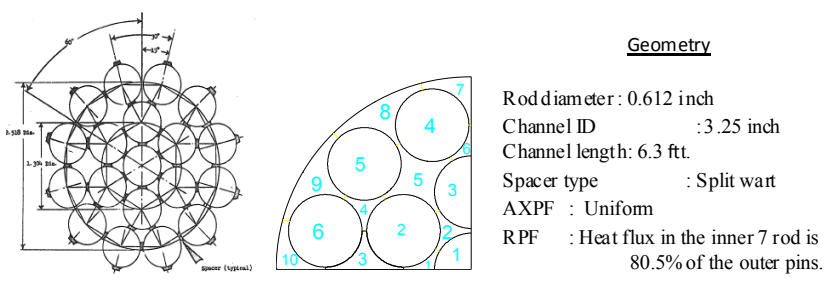

Fig. 519 rod bundle cross section and $1 / 4$ symmetry sector phenomenologically complex to analyze and also, and the criterion of the complete film disappearance is not expected to affect the prediction significantly as mentioned by Okawa [25]. Hence, in this work, a complete vanishing of the liquid film has been considered as the criterion for the dryout.

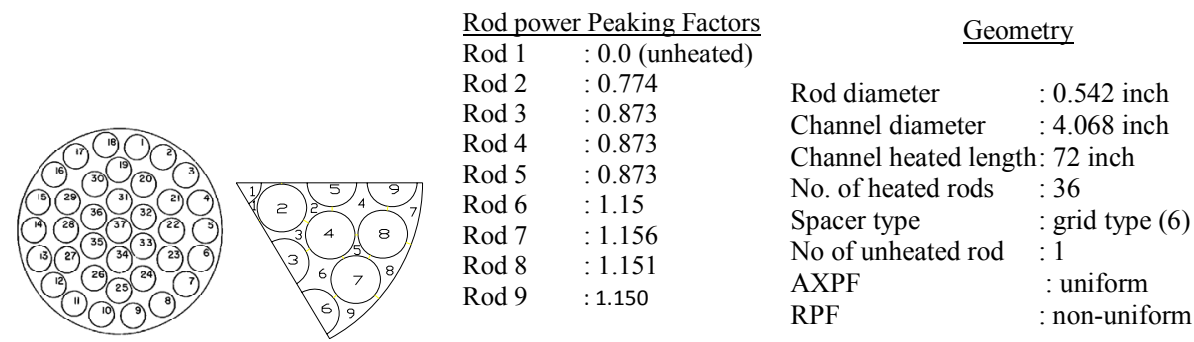

Fig. 637 Rod configuration and 1/6 Symmetry sector 


\section{Geometry considered for the Validation of FIDOM-Rod}

The FIDOM-Rod was used to predict the dryout in the 16, 37 and 19 rod bundle and compared with the experimental data available in the open literature [26, 27, 28]. Figs 4-6 depict the bundle configurations, symmetry sector considered for analysis, geometry and power profile. The range of the parameters for the data is given in Table 1

\section{Geometry of a new bundle for the prediction of critical power}

As discussed earlier a new design of bundle has been considered for AHWR [29] which is a boiling water reactor. The bundle has 54 pins and central water rod meant mainly for the emergency cooling water injection. Fig 7 depicts the rod bundle configuration with radial and axial peaking factors. The fuel rod diameter, central water rod ID and channel diameter are $11.2 \mathrm{~mm}$ and $36 \mathrm{~mm}$ and $120 \mathrm{~mm}$ respectively. The heated length is $3.5 \mathrm{~m}$.

Table 1: Range of experimental data for comparison with the FIDOM-Rod

\begin{tabular}{|c|c|c|c|c|c|c|}
\hline $\begin{array}{l}\text { Data } \\
\text { Source }\end{array}$ & $\begin{array}{c}\text { No. } \\
\text { of } \\
\text { data }\end{array}$ & $\begin{array}{c}\text { Pressure } \\
\text { (bar) }\end{array}$ & $\begin{array}{c}\text { Mass flux } \\
\left(\mathrm{kg} / \mathrm{m}^{2} \mathrm{~s}\right)\end{array}$ & \begin{tabular}{|l|} 
Inlet \\
subcooling \\
$\left({ }^{\circ} \mathrm{C}\right)$ or quality \\
$(\%) \quad$ if \\
specified \\
\end{tabular} & $\begin{array}{c}\text { Dryout } \\
\text { quality } \\
(-)\end{array}$ & $\begin{array}{l}\text { Dryout } \\
\text { power } \\
(\mathrm{MW})\end{array}$ \\
\hline $\begin{array}{ll}16 & \text { rod } \\
{[26]} & \\
\end{array}$ & 27 & $\sim 70$ & $485-1600$ & \begin{tabular}{|l|}
$27.9-$ \\
227.4
\end{tabular} & $\begin{array}{l}0.24- \\
0.686\end{array}$ & $\begin{array}{l}2.001- \\
5.358\end{array}$ \\
\hline $\begin{array}{ll}37 & \text { rod } \\
{[27]} & \\
\end{array}$ & 14 & $70-102$ & $665-1627$ & \begin{tabular}{|l|}
$0.7-$ \\
19.7 \\
\end{tabular} & $\begin{array}{l}0.299- \\
0.514 \\
\end{array}$ & $\begin{array}{l}1.544- \\
2.244\end{array}$ \\
\hline $\begin{array}{ll}19 & \text { rod } \\
{[28]} & \\
\end{array}$ & 22 & 68.95 & $1424-2712$ & $\begin{array}{l}2.2^{0} \mathrm{C}- \\
39.3 \% \\
\end{array}$ & $\begin{array}{l}0.212- \\
0.469 \\
\end{array}$ & $\begin{array}{l}0.837- \\
2.523\end{array}$ \\
\hline Over-all & 63 & $\begin{array}{l}68.95 \\
-102\end{array}$ & $485-2712$ & \begin{tabular}{|l|}
$227.41^{0} \mathrm{C}-$ \\
$39.3 \%$
\end{tabular} & $\begin{array}{l}0.212- \\
0.686\end{array}$ & $\begin{array}{l}0.837- \\
5.358\end{array}$ \\
\hline
\end{tabular}

\section{Results and Discussion}

The mechanistic modeling of liquid film dryout of rod bundle has been carried out and a mechanistic tool, FIDOM-Rod has been developed to predict the critical power of a bundle. Individual films of a subchannel facing different fuel rods with varying heat flux have been analyzed using the subchannel module as a preprocessor to the film dryout module. The cross flow of liquid film is a complex phenomena and its split into the liquid droplet in the core and the liquid film on the fuel rod is not understood. This situation poses difficulties in film modeling of the subchannel. The approach utilizes the facts that there
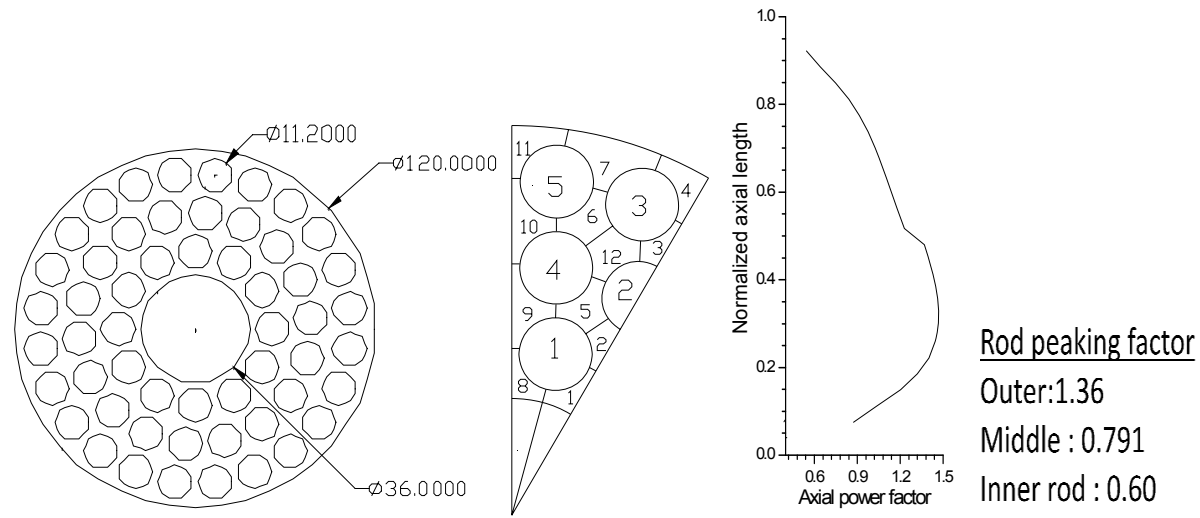

Fig.7 Schematic of 54 fuel pin Rod bundle of AHWR, 1/12 ${ }^{\text {th }}$ symmetrical sector (indicating subchannel and rod numbers) and axial power profile 
exists a strong tendency for a film flow to be uniform around the rod. The prediction has been compared with the dryout data of $16 \mathrm{rod}, 19 \mathrm{rod}$ and $37 \mathrm{rod}$ bundles having different configurations and peaking factors. Also, the constitutive models for the entrainment and deposition rates of droplets validated for a tube under BWR conditions have been incorporated in the computer code FIDOM-Rod for the dryout prediction. A good agreement between the predicted dryout power (critical power) and the experimental data indicates that the proposed approach is acceptable for the rod bundle modeling. Subsequently, the critical power of the untested 54 rod of AHWR has been determined. Important results of the analysis have been discussed in the following sections.

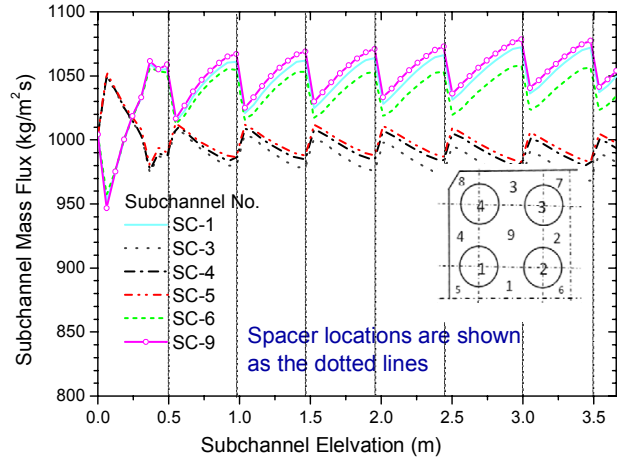

Fig. 8.1 Variation of mass flux in the subchannels of 16 rod bundle

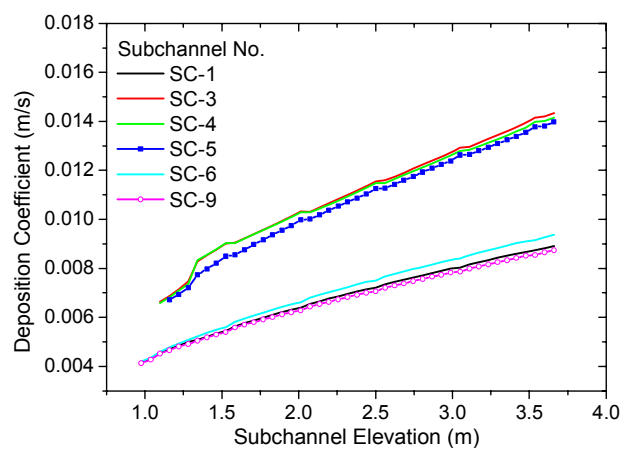

Fig. 8.3 Subchannel film flow rate for 16 rod bundle

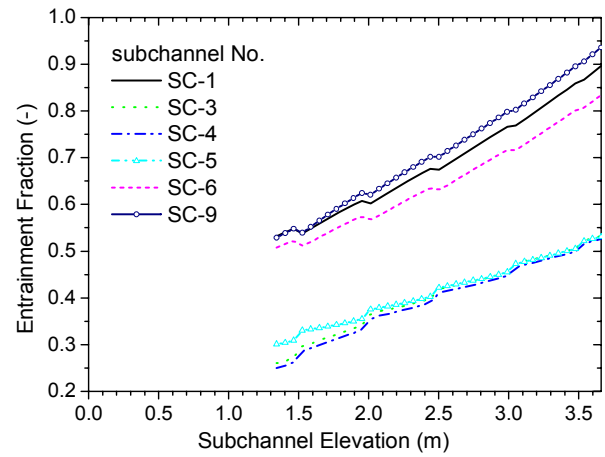

Fig. 8.2 Entrainment fraction in the subchannels of 16 rod bundle

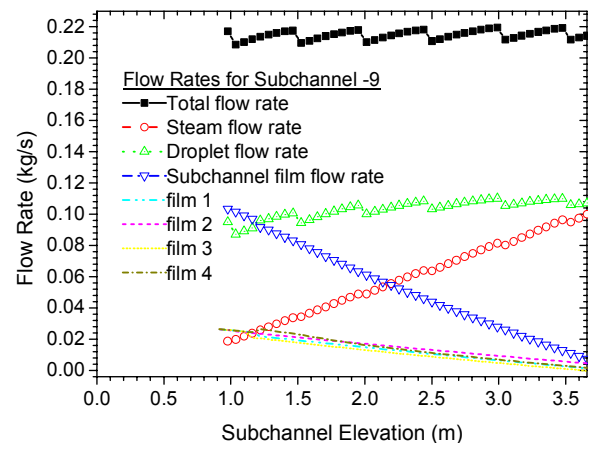

Fig. 8.4 Distribution of subchannel mass flux into the vapour, film and droplets (for the central subchannel 9)

\subsection{Validation of FIDOM-Rod with the experimental data:}

\subsubsection{Variation of droplet and film parameters in the subchannels of 16 rod bundle[26]}

Before proceeding for the prediction of the dryout for all the experimental conditions, a detailed analysis of the important parameters influencing the mechanistic prediction of dryout in the rod bundle has been carried out for a run no 7 of 16 rod bundle data [26] having heated length of $3.66 \mathrm{~m}$ which is same as that of the BWR. Fig 8.1 shows the mass variation in the subchannels. The subchannel no. 1, 3,5,6, and 9 representing different subchannel types have been considered to plot the important parameters like the entrainment fraction (E), droplet deposition or mass transfer coefficients (K), droplet concentration $(C)$ in the subchannels, mass flux $\left(m_{e}\right)$ of droplet entrainment from the film to the core and the deposition mass flux $\left(\mathrm{m}_{\mathrm{d}}\right)$ onto the liquid film. The variations of some of these parameters are depicted in fig. 8.1 to 8.4. It can be seen that the entrainment fraction (fig. 8.2) is higher for the inner subchannels $(1,6,9$ in the plot) and tends to be less in the side and corner subchannels $(3,4,5$ in the plot) which can be attributed to the presence of unheated wall in the side and corner subchannels causing film flow to be higher in absence of any evaporation. The deposition coefficient (fig. 8.3) also varies depending on the 
subchannel position having higher values for the side and corner subchannels.

Fig. 8.4 show the total flow rate, steam flow rate, droplet flow rate and film flow rate in the central subchannel (No. 9) along with the individual films of the subchannels bounded by the rods. As expected that the steam flow rate increases and the film flow rate decreases progressively along the length of the subchannel and the droplet flow rate does not change significantly. This can be attributed to fact that in the annular flow channel, there is a strong tendency of the droplets and films to achieve equilibrium. This trend is similar for other subchannel. The presence of obstacles like spacer does change the mass flux in the subchannels due to the cross flow mixing. The enhanced deposition of droplets is also observed at spacer locations (shown by dotted lines) due to change in the subchannel mixing and cross flow as can be seen in the fig 8.1. These subchannel mixing effect changes the liquid content of the subchannel also and since the dryout module determines the liquid film content, the droplet content is estimated by the differences in these fluxes. Hence, to some extent droplet deposition is enhanced in some of the subchannels.

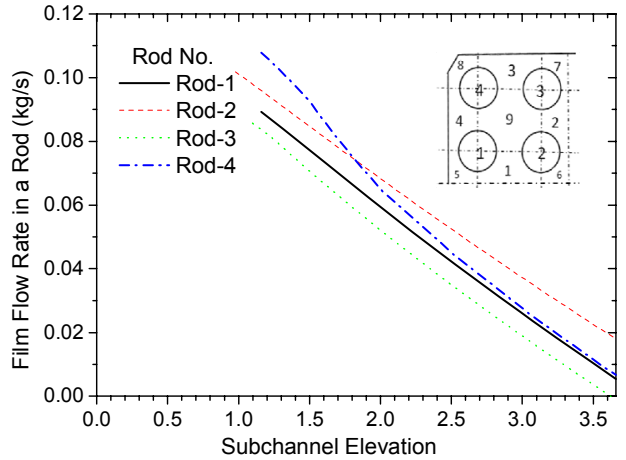

Fig9.1 Film flow rate in the 16 rod bundle

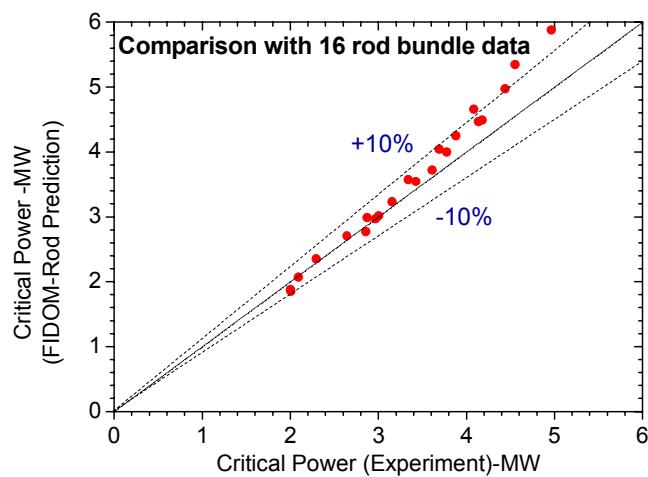

Fig. 10.1 Comparison with prediction for 16 rod bundle

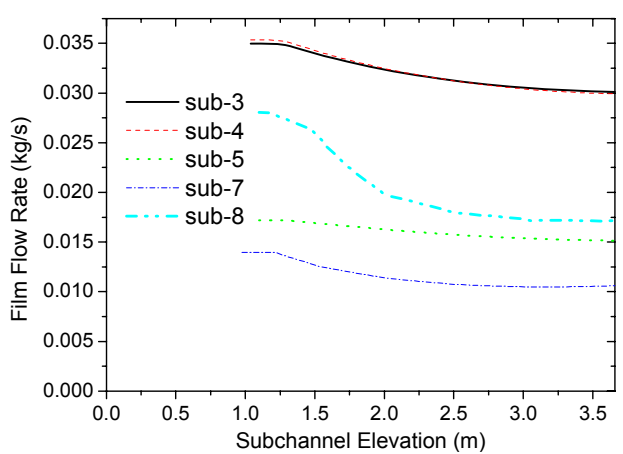

Fig. 9.2 Film flow on the unheated walls

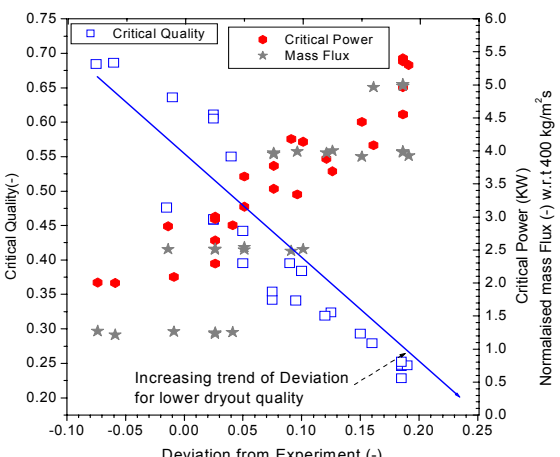

Fig. 10.2 Scattering of the data showing higher deviation for lower critical quality

Fig. 9.1 depicts the variation of film flow rate for each rod at the dryout condition. The critical rod (rod no. 3) initiating the dryout experiences a complete vanishing of the liquid flow rate. The dryout is initiated at the end of the rod due to uniform axial profile. The film flow rate on the unheated walls belonging to the subchannels $3,4,57$ and 8 is also shown in fig. 9.2. The unheated wall in the subchannels 3 and 4 has higher film flow rate owing to the larger unheated perimeters in these subchannels.

\subsubsection{Comparison with dryout data of 16 rod bundle:}

Fig. 10.1 shows the comparison between the model prediction and the experimental data. A total of 27 data has been compared with the FIDOM-Rod. It can be seen that most of the data is predicted with deviations within $\pm 10 \%$. However, the deviation is higher for the case having low dryout quality (due to very high flow rate and/or high subcooling). 
In the present analysis the dryout power below $0.25 \%$ quality is predicted within $\pm 20 \%$ accuracy. In the operating BWRs the normal operating quality is around $25 \%$ but the dryout quality is much higher (above/around 40\%) depending upon the mass flux and inlet condition. Fig. 10.2 shows the scattering of data indicating high deviation of the prediction as the critical power increases which is due to the lower dryout quality (experimental data). The LFD model is applicable for the higher dryout quality having adequate length of the annular flow region (BWR range). Thus FIDOM-Rod prediction is expected to be within $\pm 10 \%$ in the BWR quality (dryout) range.

The trend of critical power with the subcooling for different mass flux $(500,1000,1500$ and $2000 \mathrm{~kg} / \mathrm{m}^{2} \mathrm{~s}$ ) is depicted in fig. 11 and compared with the mechanistic prediction of FIDOM-Rod. The prediction is found to be excellent for 500,1000 and $1500 \mathrm{~kg} / \mathrm{m}^{2} \mathrm{~s}$. As expected the film dryout model is applicable to high quality dryout as generally observed in the BWR. However, at very high subcooling the dryout quality is lower resulting in poor prediction as shown is fig 11. The sensitivity analysis for the nodalisation on the rod film flow rate was also carried out and It was found that the number of nodes above 30 provides the same film flow rate without any significant change.

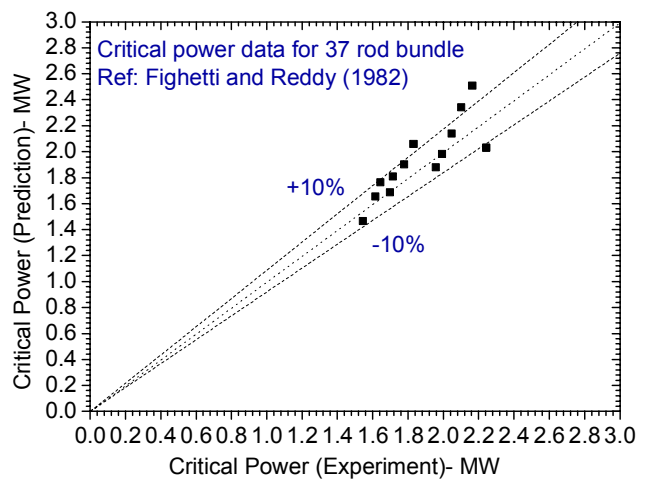

Fig. 12 Comparison between measured and predicted critical power for 37 rod bundle

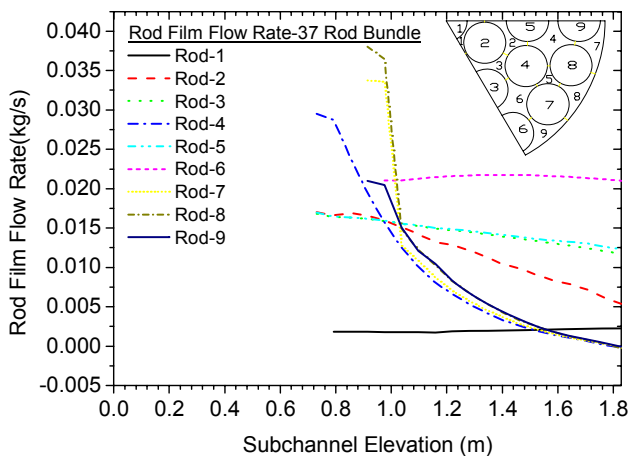

Fig.13 Rod film flow rate for 37 rod bundle at dryout (Run No -18)

\subsubsection{Comparison with dryout data of 37 rod bundle:}

14 data of the experiments in 37 rod bundle were analyzed using FIDOM-Rod. Here again, most of the prediction is made within the accuracy of $\pm 10 \%$ as shown in fig 12 . The data with higher subcooling have smaller boiling length and hence the present model cannot predict very well. The liquid film dryout out model prediction is found to be very good for a longer boiling length as the annular flow conditions prevails for a longer length (BWR condition). The film flow rate over the rods is also shown in fig. 13 for the run no. 18. The configuration of this bundle is similar to that of untested 54 rod bundle having a central unheated rod.

\subsubsection{Comparison with dryout data of 19 rod bundle:}

For the 19 rod bundle also a good agreement is obtained in the present model. Fig. 14 
depicts the comparison of the prediction of FIDOM-Rod with the 19 rod bundle data. Here again, most of the prediction is made with agreement around $\pm 10 \%$.

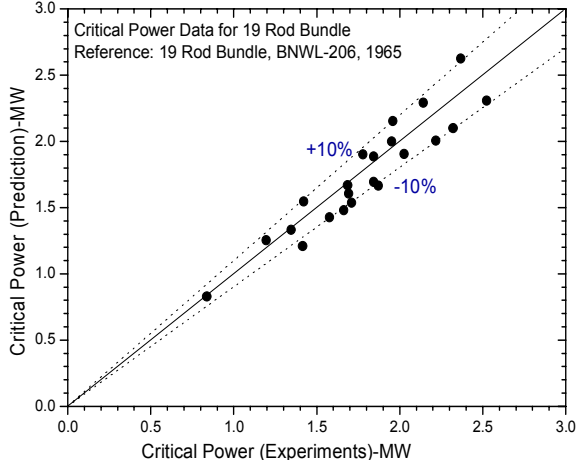

Fig. 14 Comparison between Experimental data and the prediction for19 rod bundle

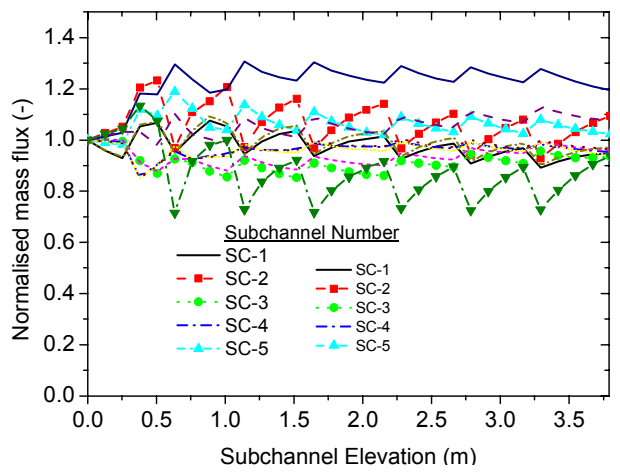

Fig. 16.1 Subchannel mass flux for 54 rod bundle

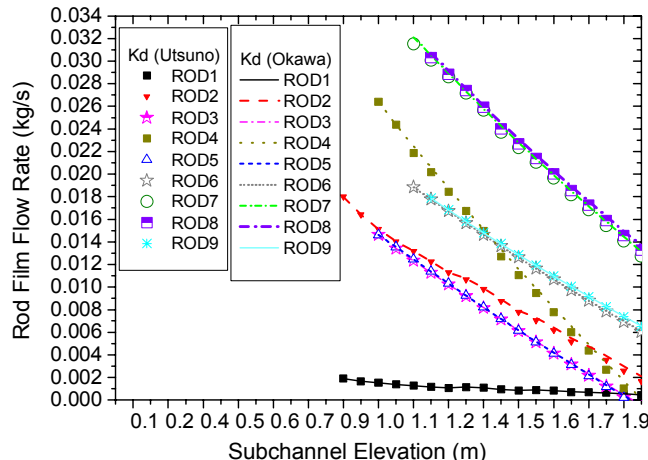

Fig. 15. Comparison of deposition coeff. $\left(\mathrm{m}^{2} / \mathrm{s}\right)$ using different models

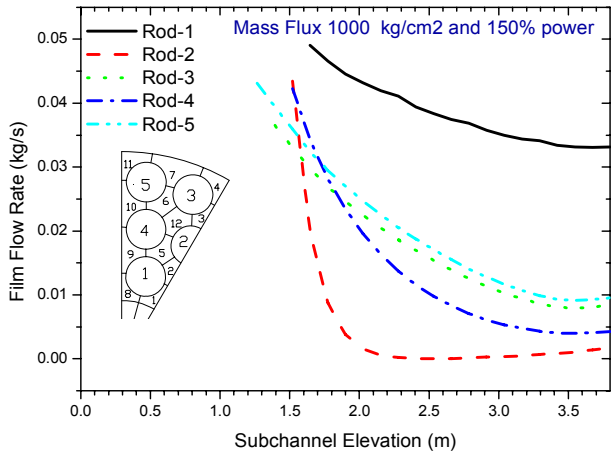

Fig. 16.2 Film Flow Rate for 54 rod bundle at $150 \%$ power and $1000 \mathrm{~kg} / \mathrm{m} 2 \mathrm{~s}$

\subsection{Comparison of the models for the droplet deposition coefficient:}

Fig. 15 depicts the variation of deposition coefficient for representative subchannels of 37 rod bundle near the dryout (run no 18) for the correlation of Okawa [25] and Utsuno [7]. For certain operating conditions during dryout analysis, the subchannel conditions was found to be beyond the range of Utsuno's model and hence it was compared with the Okawa's model to confirm the trend beyond the range. It is found that Utsuno's model agrees well with the Okawa's model even beyond the range for high quality subchannels and Okawa tends to predicts lower for the low quality channels. In the present studies Utsuno's model has been used as it has been found to provide excellent dryout prediction for a tube under BWR condition $[7,8]$.

\subsection{Critical power prediction for the 54 rod bundle of AHWR:}

Subsequent to the validation of FIDOM-rod, the prediction of critical power for the 54 rod cluster of AHWR has been carried out. Fig. 16.1 shows the variation of mass flux in the subchannels and fig. 16.2 depicts the film flow rates on the rods at $150 \%$ power corresponding to $70 \mathrm{bar}$ and $1000 \mathrm{~kg} / \mathrm{m}^{2} \mathrm{~s}$. It is seen that subchannel 3,5 and 12 has higher quality and rod 2 has the minimum film flow rate. Fig. 16.3 shows the film flow rate variation in the subchannels. The subchannels 2, 3, 5 and 12 surrounding the rod no 2 have the tendency to have lower film flow rate which results into dryout in this rod. Thus, the rod 2 is the critical rod (having maximum rod peaking of 1.36) of 54 rod bundle from dryout consideration.

Fig 17 depicts the variation of Critical Power Ratio (CPR) with mass flux at operating pressure of 70 bar and subcooling of $25{ }^{\circ} \mathrm{C}$. The trend of CPR indicates that the critical power of a bundle initially increases sharply with the mass flux upto $800 \mathrm{~kg} / \mathrm{ms}^{2} \mathrm{~s}$ and 
subsequently the increase is not significant upto $1400 \mathrm{~kg} / \mathrm{ms}^{2} \mathrm{~s}$ beyond which there is a tendency to increase further. The critical power ratio was found to be 1.52 for the mass flux of $942 \mathrm{~kg} / \mathrm{m}^{2} \mathrm{~s}$ which is the flow under normal operating condition. Since the mass flux of the bundle reduces with the reactor power, the critical power of a reactor will be less than 1.52. Fig. 17 also shows the reduction in the channel flow rate as the power is increased. The interaction of these two graphs indicates the operating point at the critical power of the bundle. The critical power ratio the bundle has been determined to be 1.49 .

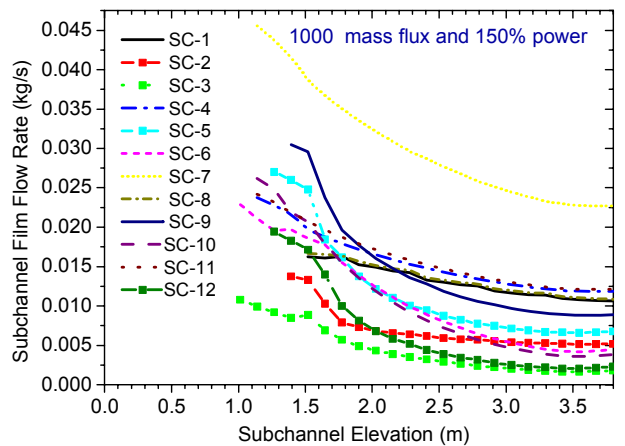

Fig. 16.3 Subchannel Film flow rate for 54 rod bundle at $150 \%$ power and $1000 \mathrm{~kg} / \mathrm{m}^{2} \mathrm{~s}$

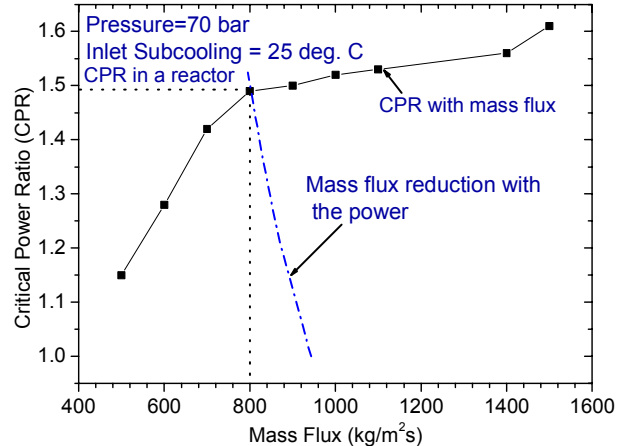

Fig 17. Critical power of 54 rod bundle and channel flow varation with power

Thus the proposed approach of uniform film flow assumption around the rod is expected to provide a reasonable prediction for this untested 54 rod bundle. The approach will be further validated with the full scale test data of 54 rod bundle once the dryout experiments is conducted in the facility being constructed in BARC.

\section{Conclusion:}

The following conclusion can be made in the present work.

1) The dryout modeling of the rod bundle using the liquid film analysis in the annular flow is found to agree well (within $\pm 10 \%$ ) with the data of 16, 3719 and rod assemblies under BWR conditions. Thus the concept of dryout modeling in a tube can be extended to the rod bundle also using the local conditions determined by the subchannel code.

2) The validation of FIDOM-Rod confirms that uniform liquid film flow rate around the rod can be considered for the mechanistic prediction of the dryout in the rod bundle. The validation of this approach is limited in the literature. The cross flow modeling of the liquid film in the rod is an important aspects of mechanistic prediction in the rod bundle and in absence of appropriate approach for the complex phenomena of the liquid film cross flow in the subchannels, the proposed approach can be employed for dryout modeling in the bundle.

3) The deposition model and entrainment model selected for the CHF in tube has also been found to be adequate for the rod bundle under BWR conditions. This shows that subchannel is a good representation of the tube for the liquid film dryout analysis when cross flow and inter subchannel mixing is accounted in the analysis.

4) The trend of the critical power with the inlet subcooling agrees well with the data and it increases almost linearly with increase in the subcooling.

5) The mechanistic model has been applied to the untested 54 rod bundle of AHWR. The rod no. 2 in the middle ring of the bundle seems to experience the dryout. The critical power ratio has been found to be 1.49 while accounting for the channel flow reduction at the $\mathrm{CHF}$ as compared to flow corresponding to the normal power. Unlike the MCHFR approach, the CPR approach indicates absolute power margin available in the bundle. Considering the margins required for the operating flexibility and associated uncertainties, 
there is a possibility of power enhancement in 54 rod bundle from the CHF consideration.

6) Even without the spacer model, significantly good dryout prediction was obtained in the present approach for the rod bundles under BWR conditions considered in this study. The enhancement of the droplet deposition due to spacer is highly geometric dependent and models developed are proprietary in nature. Incorporation of the spacer effect is expected to improve the prediction of dryout.

7) The good prediction accuracy of FIDOM-Rod without incorporating the spacer model could be due to the proposed approach of the uniform film flow around the rod and it seems that this approach to some extent simulated the tendency of the spacers to distribute the film over the rods. This needs to be further confirmed by validating with other dryout data for different bundle configurations. Also, the subchannel module considers the cross flow mixing due to the spacer and the dryout model changes the droplet concentration depending upon the liquid film as determined by the dryout module. However, to capture the spacer with the swirling vanes, more intensive CFD near the spacer is needed as the liquid droplet deposition is enhanced considerably. The droplet deposition rate can be analyzed with detailed analysis in the vicinity of the spacers which can be plugged into the FIDOM-Rod.

8) Since the present approach predicts the critical power within the accuracy of $\pm 10 \%$ for the BWR rod assemblies the approach can be followed at the design stage to study the effect of rod configuration, radial and axial peaking factors and other operating parameters like inlet subcooling and flow rates on the critical power and hence the safety margins available in the bundle. The full scale test on the rod bundle can be used to tune the code to further improve the prediction.

\section{Acknowledgement}

The support provided by JSPS (Japanese Society for Promotion of Science) for carrying out this research, encouragement by Dr. N. Watanabe, RLNR, Tokyo Institute of Technology, Tokyo, Japan, Mr. K. K. Vaze, Associate Director, Reactor Design and Development Group, BARC and useful discussion with Mr. A. Dasgupta, BARC are highly appreciated.

\section{References}

[1] Groeneveld, D.C., Leung, et. al., 1996, The 1995 look-up table for critical heat flux in tubes, Nucl. Eng. Des., Vol. 163, 1-23.

[2] Levy S., Heazler J. M., and Abdollanhian D., 1981, Prediction of critical heat flux in vertical pipe flow, Nucl. Eng. Des., 65, 131-140.

[3] Saito T., Hughes F. D. and Carbon M. W., 1978, Multi-fluid modelling of annular two-phase flow, Nucl. Eng. Des., Vol. 50, 225-271.

[4] Katto Y., 1984, Prediction of critical heat flux for annular flow in tubes taking into account the critical liquid film thickness concept, Int. J. Heat Mass Transfer, Vol. 27, No. 6, 883-891.

[5] Sugawara S., 1990, Analytical prediction of CHF by FIDAS code based on three-fluid and film dryout model, J. Nucl. Sci. and Tech., Vol. 27, No. 1, 12-29.

[6] Hoyer, N., 1998, Calculation of dryout and post dryout heat transfer for tube geometry, Int., J. Multiphase flow, Vol 24, No. 2, 319-334.

[7] Utsuno H. and Kaminaga F., 1998, Prediction of liquid film dryout in two-phase annular mist flow in an uniformly heated narrow tube: Development of analytical method under BWR conditions, J. Nucl. Sci. and Tech, 35, 9, 643-653. 
[8] D. K. Chandraker P. K. Viajayan, M. Aritomi., 2011, Phenomenological prediction of CHF under boiling water reactor (BWR) conditions", Progress in Nuclear Energy, (53), 874-880.

[9] Tomiyama, O. Yokomizo, 1988, Spacer effects on film flow in BWR fuel bundle, J. Nucl. Sci. Technol., 25[2], 204-206.

[10] Nishida K., T. Kanazawa, O. Yokomizo, Y. Masuhara, 1994 "Spacer effect on liquid film flow and critical power in BWR fuel bundles,” J. Nucl. Sci. Technol., 31[3], 213-221.

[11] Kanazawa, T., Nishida, K., Nagayoshi, T. et al., 1995, Critical power evaluation with consideration of differences in droplet behavior due to spacer shape influence, J. Nucl. Sci. Technol., 32[4], 301-312.

[12] Sugawara S., Sakai T., et al., 1989, Subchannel analysis by the FIDAS code based on the three-fluid model, Proc. 4th Int. Topical Mtg. (NURETH-4), Karlsruhe,Oct.10-13,Vol. 1. [13] Naitoh M., Takashi Ikeda, et al. 2002, Critical Power analysis with mechanistic models for nuclear fuel bundles, (I), J. Nucl. Sci. Technol., Vol. 39, No.1, 40-52.

[14] Mitsutake T. et al., 1990, Subchannel analysis of a critical power test, using simulated BWR 8X8 fuel assembly, Nucl. Eng. Des., Vol. 122, 235-254.

[15]Whalley P. B., 1978, The calculation of dryout in a rod bundle- a comparison of experimental data and calculated results, Int. J. Multiphase flow, Vol. 4, 427-431.

[16] Adamsson C., Corre J. L., 2011, Modeling and validation of a mechanistic tool (MEFISTO) for the prediction of critical power in BWR fuel assemblies. Nucl. Eng. Des., Vol. 241, 2843-2858.

[17] Wheeler, C.L. et al., 1976, COBRA-IV-I: An interim version of COBRA for thermal-hydraulic analysis of rod bundle nuclear fuel elements and cores", BNWL-1962.

[18] Whalley P.B., 1977, The calculation of dryout in a rod bundle, Int. J. Multiphase flow, Vol. 3, 501-515.

[19] Butterworth, D., 1968, Air-water climbing film flow in an eccentric annulus. Int. Symposium on Research in Co-current Gas-Liquid Flow, University of Waterloo, Ontario, Paper B2.

[20] Whalley, P. W., 1978, Boiling, condensation and gas-liquid flow, Clarendon Press, Oxfort, USA.

[21] Ishii, M., Mishima, K., 1981, Correlation for liquid entrainment in annular two-phase flow of low-viscous fluid, ANL/RAS/LWR81-2.

[22] Paleev, I.I., Filippovich, B. S., 1966, Phenomena of liquid transfer in two-phase dispersed annular flow, J. Heat Mass Transfer, 9, 1089-1093.

[23] Okawa, T., et.al., 2004, Prediction of the critical heat flux in annular regime in various vertical channels, Nucl. Eng. and Des. Vol.229, 223-236.

[24] Ishii, M, Grolmes, M. A., 1975, Inception criteria for droplet entrainment in two-phase concurrent film flow, AICHE J., 21[2], 308-318.

[25] Okawa, T., Kotani, A., Kataoka, I., Naito, M., 2003, Prediction of critical heat flux in annular flow using a film flow model. J. Nucl. Sci. Technol., 40, 388.

[26] Lucchini F., Marinelli, V., 1974, Experimental data on burnout in a simulated BWR fuel bundle, Nucl. Eng. Des., Vol.31, 371-378.

[27] Fighetti C. F., Reddy D. G., 1982, Parametric study of CHF Data, Vol 3, Part 2 : Critical Heat Flux Data, EPRI-NP-2609-Vol. 3-Part-2.

[28] Hesson, Fitzsimons, Batch, Experimental Boiling Burnout Heat Fluxes with an electrically heated 19 rod bundle test section, BNWL-206, 1965.

[29] Sinha, R.K., Kakodkar, A., 2006, Design and development of the AHWR-the Indian thorium fuelled innovative nuclear reactor, Nucl. Eng. Des., Vol. 236, 683-700. 